\title{
Defining the role for PET myocardial blood flow early post cardiac transplant
}

\author{
Robert J. H. Miller, MD (1), a and Daniel S. Berman, MD $^{\mathrm{b}}$ \\ a Department of Cardiac Sciences, University of Calgary, Calgary, AB, Canada \\ b Department of Imaging, Medicine, and Biomedical Sciences, Cedars-Sinai Medical Center, Los \\ Angeles, CA
}

Received Aug 13, 2020; accepted Aug 14, 2020

doi: $10.1007 / \mathrm{s} 12350-020-02345-4$

\section{See related article, pp. 712-723}

With advances in the care of cardiac transplant patients over the last 50 years, cardiac allograft vasculopathy (CAV) has become an increasingly important long-term complication. ${ }^{1} \mathrm{CAV}$ is the most common indication for re-transplantation in patients who survive at least one year and is a leading cause of graft failure and death in patients who survive at least 3-year posttransplant. ${ }^{2}$ While many transplant programs perform surveillance invasive coronary angiography (ICA), often with intravascular ultrasound, there is mounting evidence for non-invasive monitoring with positron emission tomography (PET).$^{3-8}$ PET with myocardial blood flow (MBF) measurement for CAV surveillance has a strong pathophysiologic rationale since it can detect the diffuse epicardial and microvascular disease characteristic of CAV.

In this issue, Wiefels et al. evaluated the clinical utility of serial PET myocardial blood flow (MBF) measurements in 121 patients early post-transplant. ${ }^{9}$ The authors demonstrate that patients with an abnormal stress MBF (defined as <2.1) on the baseline PET study and those with persistently elevated coronary vascular resistance (defined as $>76$ ) were more likely to experience adverse cardiovascular events. ${ }^{9}$ This study suggests that PET has a clinical role for CAV diagnosis

Reprint requests: Robert J. H. Miller, MD, Department of Cardiac Sciences, University of Calgary, GAA08, 3230 Hospital Drive NW, Calgary, $\mathrm{AB} \mathrm{T} 2 \mathrm{~N} \quad 2 \mathrm{~T} 9$, Canada; robert.miller@alberta healthservices.ca

J Nucl Cardiol 2022;29:724-6.

$1071-3581 / \$ 34.00$

Copyright (C) 2020 American Society of Nuclear Cardiology. and risk stratification early post-transplant and also confirms the potential benefits of serial PET measurements. Feher et al. recently demonstrated that serial evaluation of coronary flow reserve (CFR), with abnormal defined as $<1.5$, resulted in a significant reclassification in risk of all-cause mortality. ${ }^{8}$ Additionally, baseline CFR and change in CFR between PET studies were the only significant predictors of all-cause mortality in multivariable analysis. ${ }^{8}$

The most important, novel aspect of the study by Wiefels et al. was the early nature of the PET assessments. PET studies were performed at a mean of 1.4 and 2.6 years post-transplant for baseline and follow-up studies, respectively. Previous studies have investigated patients between 4.8 and 12.5 years post-transplant. ${ }^{3-8}$. Prior to the current study, the utility of PET early posttransplant represented an important knowledge gap because proliferation signal inhibitors (PSI) may be more effective in patients with early CAV. In a prior study of 402 patients post cardiac transplant, transition to PSI in the first two years post-transplant was associated with slower progression of CAV and reduced allcause mortality compared to later transition. ${ }^{10}$ However, PSI is not typically initiated immediately post-transplant due to delayed wound healing and infections. ${ }^{11}$ Additionally, routine transition to PSI is problematic because many patients are unable to tolerate chronic therapy. ${ }^{11}$ The results from Wiefels et al. support a role for PET MBF early post-transplant to target PSI therapy for patients who are at higher risk of progressive CAV or adverse events.

There are a few important limitations to the study by Wiefels et al. The study was not adequately powered to assess multiple variables, such as regional perfusion abnormalities, and used a composite outcome which included diagnostic (progressive CAV) and prognostic endpoints. Studies were collected during routine clinical care, and there was most likely ascertainment bias due to 
patients with abnormal PET parameters being preferentially referred for ICA. Lastly, the authors only demonstrated significant results with new PET thresholds, but not with several previously described values. While this could reflect a need for different thresholds early post-transplant, it could also simply reflect the lack of statistical power. Importantly, we recently validated the diagnostic and prognostic utility of previously defined thresholds in a study of patients later posttransplant. ${ }^{6}$ Currently, a lack of standardization for diagnostic or prognostic thresholds is a barrier to broader implementation of PET for CAV surveillance.

There is mounting evidence that PET may be a superior modality for CAV surveillance. Dobutamine stress echocardiography has limited sensitivity for detecting mild CAV and inducible ischemia is not associated with cardiovascular events. ${ }^{12}$ The diagnostic accuracy of SPECT MPI has been variably reported, with sensitivity and specificity ranging from 13 to $92 \%$ and $55 \%-98 \%$, respectively, due to differences in patient populations and definitions of CAV. ${ }^{13-15}$ Additionally, the prognostic utility of SPECT in cardiac transplant patients is unclear. ${ }^{16,17}$ Cardiac computed tomography angiography has good diagnostic accuracy for mild CAV (sensitivity 97\%, specificity $81 \%$ ), ${ }^{18}$ which can potentially be improved by including quantitative assessment of plaque volumes. ${ }^{19}$ However, its prognostic value has not been defined and accuracy may be lower in non-expert centers, due to the technical challenge inherent in imaging cardiac transplant patients who have high resting heart rates.

Surveillance for CAV is typically performed to diagnose patients with early stages of CAV or to riskstratify patients with known CAV. Current evidence supports the use of PET MBF, and potentially CCTA in experienced centers, to identify patients with early CAV who may benefit from PSI therapy. Additionally, there is robust evidence for using PET MBF to risk-stratify patients with established CAV to potentially guide decisions regarding revascularization or re-transplantation. ${ }^{20}$ Large, multicenter efforts are needed to more rapidly advance the field and provide clarity regarding optimal implementation of PET for CAV surveillance.

\section{Disclosures}

Dr. Daniel Berman receives royalties for QPS software at Cedars-Sinai. Dr. Miller has no relevant conflicts of interest.

\section{References}

1. Chih S, Chong AY, Mielniczuk LM, Bhatt DL, Beanlands RS (2016) Allograft vasculopathy: The achilles' heel of heart transplantation. J Am Coll Cardiol 68:80-91

2. Khush KK, Cherikh WS, Chambers DC, Harhay MO, Hayes D Jr, Hsich E et al (2019) The International Thoracic Organ Transplant Registry of the International Society for Heart and Lung Transplantation: Thirty-sixth adult heart transplantation report - 2019; focus theme: Donor and recipient size match. J Heart Lung Transplant 38:1056-1066

3. Chih S, Chong AY, Erthal F, deKemp RA, Davies RA, Stadnick E et al (2018) PET assessment of epicardial intimal disease and microvascular dysfunction in cardiac allograft vasculopathy. J Am Coll Cardiol 71:1444-1456

4. Mc Ardle BA, Davies RA, Chen L, Small GR, Ruddy TD, Dwivedi $G$ et al (2014) Prognostic value of rubidium-82 positron emission tomography in patients after heart transplant. Circ Cardiovasc Imaging 7:930-937

5. Bravo PE, Bergmark BA, Vita T, Taqueti VR, Gupta A, Seidelmann $S$ et al (2018) Diagnostic and prognostic value of myocardial blood flow quantification as non-invasive indicator of cardiac allograft vasculopathy. Eur Heart J 39:316-323

6. Miller RJH, Manabe O, Tamarappoo B, Hayes S, Friedman JD, Slomka PJ et al (2020) Comparative prognostic and diagnostic value of myocardial blood flow and myocardial flow reserve after cardiac transplantation. J Nucl Med 61:249-255

7. Miller RJH, Kobashigawa JA, Berman DS (2019) Should positron emission tomography be the standard of care for non-invasive surveillance following cardiac transplantation? J Nucl Cardiol 26:655-659

8. Feher A, Srivastava A, Quail MA, Boutagy NE, Khanna P, Wilson L et al (2020) Serial assessment of coronary flow reserve by rubidium-82 Positron emission tomography predicts mortality in heart transplant recipients. JACC Cardiovasc Imaging 13:109120

9. Wiefels C, Almufleh A, Yao J, de Kemp RA, Chong AY, Mielniczuk LM et al (2020) Prognostic utility of longitudinal quantification of PET myocardial blood flow early post heart transplantation. J Nucl Cardiol

10. Asleh R, Briasoulis A, Kremers WK, Adigun R, Boilson BA, Pereira NL et al (2018) Long-term sirolimus for primary immunosuppression in heart transplant recipients. J Am Coll Cardiol 71:636-650

11. Eisen HJ, Kobashigawa J, Starling RC, Pauly DF, Kfoury A, Ross $\mathrm{H}$ et al (2013) Everolimus versus mycophenolate mofetil in heart transplantation: A randomized, multicenter trial. Am J Transplant 13:1203-1216

12. Clerkin KJ, Farr MA, Restaino SW, Ali ZA, Mancini DM (2016) Dobutamine stress echocardiography is inadequate to detect early cardiac allograft vasculopathy. J Heart Lung Transplant 35:10401041

13. Manrique A, Bernard M, Hitzel A, Bubenheim M, Tron C, Agostini D et al (2010) Diagnostic and prognostic value of myocardial perfusion gated SPECT in orthotopic heart transplant recipients. J Nucl Cardiol 17:197-206 
14. Wu YW, Yen RF, Lee CM, Ho YL, Chou NK, Wang SS et al (2005) Diagnostic and prognostic value of dobutamine thallium201 single-photon emission computed tomography after heart transplantation. J Heart Lung Transplant 24:544-550

15. Payne GA, Hage FG, Acharya D (2016) Transplant allograft vasculopathy: Role of multimodality imaging in surveillance and diagnosis. J Nucl Cardiol 23:713-727

16. Aguilar J, Miller R, Tamarappoo B, Hayes SW, Friedman J, Slomka $P$ et al (2020) Limited prognostic ability of SPECT in the heart transplant population: Analysis from a single large-volume center. Abstract. J Am Coll Cardiol 75:1643

17. Veenis JF, Boiten HJ, van den Berge JC, Caliskan K, Maat APWM, Valkema R et al (2019) Prediction of long-term cardiovascular outcomes in heart transplant recipients: Value of stress technetium-99m tetrofosmin myocardial perfusion imaging. J Nucl Cardiol 26:845-852

18. Wever-Pinzon O, Romero J, Kelesidis I, Wever-Pinzon J, Manrique C, Budge D et al (2014) Coronary computed tomography angiography for the detection of cardiac allograft vasculopathy: A meta-analysis of prospective trials. J Am Coll Cardiol 63:19922004

19. Miller RJH, Kwiecinski J, Shah KS, Eisenberg E, Patel J, Kobashigawa JA et al (2019) Coronary computed tomographyangiography quantitative plaque analysis improves detection of early cardiac allograft vasculopathy: A pilot study. Am J Transplant 20:1375

20. Miller RJH, Clarke BA, Howlett JG, Khush KK, Teuteberg JJ, Haddad F (2019) Outcomes in patients undergoing cardiac retransplantation: A propensity matched cohort analysis of the UNOS Registry. J Heart Lung Transplant 38:1067-1074

Publisher's Note Springer Nature remains neutral with regard to jurisdictional claims in published maps and institutional affiliations. 